\author{
SPINAL DURAL ARTERIOVENÖZ FISTÜL DENEYIMIMIZ: 4 OLGU SUNUMU \\ Zeynep Ezgi BALÇIK*, Merve YATMAZOĞLU*, Songül ŞENADIM*, Mücahid ERDoĞAN*, \\ Hatem Hakan SELÇUK**, Batuhan KARA**, Hayrunisa Dilek ATAKLI* \\ *Bakırköy Prof. Dr. M. Osman Ruh Sağlığı ve Sinir Hastalıkları Eğitim ve Araştırma Hastanesi, \\ Nöroloji Kliniği, İSTANBUL \\ **Bakırköy Dr. Sadi Konuk Eğitim ve Araştırma Hastanesi, Nöroradyoloji Kliniği, İSTANBUL
}

ÖZET

Dural arter ve perimedüller venöz sistem arasında oluşan düşük akıma sahip şantların sebep olduğu spinal dural arteriovenöz fistül, ilerleyici miyelopati tablosu ile seyreder. Siklıkla torakolomber bölgede saptanır. Geri dönüşsüz özürlülüğe sebep olabilmesi nedeniyle ayırıcı tanının doğru yapılması önemlidir. Biz bu miyelopati bulgularıyla seyreden, spinal dural arteriovenöz fistül tanısı alan ve farklı șekillerde sonuçlanan 4 olguyu klinik ve radyolojik olarak tartışmayı amaçladık.

Anahtar Sözcükler: Spinal dural artiovenöz fistül, endovasküler, spinal arteriovenöz malformasyon.

\title{
OUR EXPERIENCE OF SPINAL DURAL ARTERIOVENOUS FISTULA: 4 CASE REPORTS
}

\section{ABSTRACT}

Spinal dural arteriovenous fistula, which is caused by the low flow shunts between dural arteries and the perimedullary venous system shows progressive myelopathy signs. It is usually found in the thoracic region. It is vital to accurately make differential diagnosis since the disease may cause irreversible injury. In this report we aimed to discuss four cases of spinal arteriovenous fistula that showed different outcomes.

Key Words: Spinal dural arteriovenous fistula, endovascular, Spinal arteriovenous malformation.

\section{GíRiş}

Spinal vasküler lezyonlar geniş klinik spektruma sahip olup, santral sinir sisteminin tüm vasküler malformasyonlarının yaklaşık \%5-9'unu oluşturur (1). American/English/French (ABF) connection sinıflamasına göre 4 grupta incelenirler. Bunlar Tip 1; spinal dural arteriovenöz fistül (SDAVF), Tip 2; intramedüller glomustip arteriovenöz malformasyon, Tip3; jüvenil-tip arteriovenöz malformasyon, Tip 4; perimedüller arterio-venöz fistüldür (1). Nadir görülen bu malformasyonlar içinde \%50-85 oranında görülen SDAVF tipik manyetik rezonans görüntüleri ve tedaviye cevap oranları açısından önemlidir. SDAVF, erkeklerde kadınlardan 5 kat daha fazla görülmekte ve 50-60 yaş arasında sıklığı artmaktadır (2). Klinik seyri yavaş ve ilerleyicidir. Sıklıkla torakolomber (T6-L2) bölgede, bir radikülomedüller arter ile perimedüller ven arasındaki fistül oluşumu ile meydana gelir (2). Tanıda dijital substraksiyon anjiyografisi (DSA) altın standarttır (3).

Tedavisi hastanın durumuna ve fistülün özelliklerine göre hızlı endovasküler embolizasyon veya cerrahi ligasyondur (4). Tedavi edilmediği takdirde hastalık ciddi morbiditeye ve geri dönüşü olmayan özürlülüğe neden olabilir. $\mathrm{Bu}$ yazıda hastanemiz nöroloji kliniğinde SDAVF tanısı ile takip edilen 4 olguyu klinik, görüntüleme özellikleri ve tedavi yöntemleriyle birlikte tartışarak sunmayı amaçladık.

\footnotetext{
Yazışma Adresi: Dr. Zeynep Ezgi Balçık Bakırköy Ruh ve Sinir Hastalıkları Hastanesi Nöroloji Kliniği, İstanbul

Tel: $02124091515 \quad$ E-posta: zeynepezgi33@hotmail.com

Gelis Tarihi: $16112017 \quad$ Kabul Tarihi: 19.12 .2017

Received: 16.11.2017 Accepted: 19.12.2017

Bu makale şu şekilde atıf edilmelidir: Balçık Z. E, Yatmazoğlu M, Şenadım S, Erdoğan M, Selçuk H. H, Kara B, Ataklı H. D. Spinal dural arteriovenöz fistül deneyimimiz: 4 olgu sunumu. Türk Beyin Damar Hastalıkları Dergisi 2017; 23(3): 91-96. doi: 10.5505/tbdhd.2017.99705
} 


\section{OLGU SUNUMLARI}

OLGU 1: 44 yaşında erkek hasta 2 yll önce başlayan, son 1 aydır artış gösteren bacaklarda ve kollarda güçsüzlük, 15 gündür eklenen idrar ve gaita inkontinansı şikayetleriyle başvurdu. Özgeçmiş ve soygeçmişinde özellik yoktu. Nörolojik muayenesinde; kas gücü her iki üst ve alt ekstremitede 4/5 idi. Duyu muayenesinde üst ekstremitede $\mathrm{C} 5$, gövdede ise T8 düzeyinin altında hipoestezi mevcuttu. Taban cildi refleksleri bilateral ekstansör, derin tendon refleksleri ise global olarak hiperaktifti. Spinal manyetik rezonans görüntülemede (MRG) C2'den başlayıp L1'e kadar uzanan spinal kordun posteriorunda intradural mesafede belirgin signal void özellikte vasküler yapılar izlendi (Resim 1A-1B). Spinal DSA'da sağ D7 ve D8 spinal arterlerden dolan SDAVF saptand. Selektif olarak sağ interkostal arterin posterior spinal arter dalına girilerek fistül lokalizasyonuna ulaşılıp oradan mikrokateter içerisinden embolik bir ajan olan ethylene-vinyl alcohol copolymer (SQUID, BALT, Paris, France) ile total olarak embolizasyon yapıldı. Hastanın 1 hafta sonraki nörolojik muayenesi sol alt ekstremitede hipoestezi ve bilateral kalça fleksiyonunda hafif parezi dışında normaldi.

OLGU 2: 55 yaşında erkek hasta 5 ay önce düşme sonrası başlayan bacaklarda güçsüzlük ve idrar kaçırma şikayetleriyle başvurdu. Özgeçmişinde diabetes mellitus nedeniyle oral antidiyabetik kullanımı mevcuttu. Nörolojik muayenesinde kas gücü her iki alt ekstremite proksimalinde $3 / 5$, distalinde $4 / 5$ düzeyindeydi. Derin tendon refleksleri ise global olarak hiperaktifti. Taban cildi refleksleri bilateral ekstansördü. Duyu muayenesinde T9 seviyesinin altında hipoestezi mevcuttu. Spinal MRG'de C5 düzeyinden başlayarak lomber düzeylere kadar devam eden en geniş yerinde yaklaşık $5 \mathrm{~mm}$ olan T1'dehipointens, T2'de hiperintens, kontrast tutulumu izlenen lezyon, aynı bölgede aralıklı olarak signalvoid özellikte vasküler yapılar izlendi (Resim 2A-2B2C). Elektromyelografi'de de solda belirgin iki yanlı L4 segment innervasyonlu kaslarda nörojen bulgular saptandl. Spinal DSA'da sol L3 pedikülünden beslenen SDAVF saptandl. Ancak hasta servis takip sırasında myokard enfarktüsü nedeni ile kaybedildiğinden tedavisi yapılamadı.
OLGU 3: 48 yaşında erkek hasta 10 gündür mevcut olan yürüyememe şikayeti ile nöroloji polikliniğine başvurdu. 4-5 yıldır var olan, yürüme güçlüğü ve merdiven çlkmakta zorlanma şikayetleriyle dış merkezde herediter spastik paraparezi tanısı aldığı öğrenildi. Esansiyel trombositoz sebebiyle hidroksiüre ve asetil salisilik asit $100 \mathrm{mg} /$ gün kullanıyordu. Nörolojik muayenesinde kas gücü üst ekstremitelerde tam, alt ekstremitelerde ise 2/5 düzeyindeydi. Derin tendon refleksleri üst ekstremitelerde normoaktif olup alt ekstremitelerde hiperaktifti. Duyu muayenesinde T8 seviyesi altında hipoestezi mevcuttu. Taban cildi refleksi bilateral ekstansör idi. Çekilen spinal MRG'sinde spinal kordda $\quad$ T4 düzeyinden başlayarak distale uzanan T2 sekansta hiperintens sinyal değişikleri ve ekspansiyon, T1 kontrastll kesitlerde heterojen kontrastlanma izlendi (Resim 3A-3B). Spinal DSA'da sol D5 ve D6 interkostal arterden beslenen SDAVF izlendi. Selektif olarak sol interkostal arterin posterior spinal arter dalına girilerek fistül lokalizasyonuna ulaşılıp oradan mikrokateter içerisinden embolik bir ajan olan ethylene-vinyl alcohol copolymer (SQUID, BALT, Paris, France) verilen ancak $2 \mathrm{kez}$ denenmesine rağmen total olarak embolize edilemeyen hastaya nöroşirürüji tarafından cerrahi ligasyon yapıldı. Kontrol spinal DSA'da SDAVF'nin total olarak kapatıldığı gözlendi. Hastanın bir ay sonraki muayenesinde parezisinde düzelme olmadı, duyu kusuru devam etmekteydi.

OLGU 4: 62 yaşında erkek hasta 3 aydır var olan, giderek artış gösteren her iki bacakta güçsüzlük ve duyu kusuru şikayetleriyle tarafımıza başvurdu. Özgeçmişinde kardiyak aritmi sebebiyle kalsiyum kanal blokeri kullanımı mevcuttu. Nörolojik muayenesinde her iki alt ektremitede kas gücü 1/5 düzeyindeydi, derin tendon refleksleri alt ekstremitede alınamadı. Uzun eldiven çorap tarzı duyu kaybı mevcuttu. Taban cildi refleksleri sağda lakayt, solda dorsaldi. EMG'de alt ekstremitede üst motor nöron tipi seyrelme saptandı. Çekilen spinal MRG'de C3 seviyesinden başlayan, T12'ye kadar uzanan, T2A'da milimetrik dilate signal void vasküler yapılar ve torakal bölgeden konuş medullarise uzanan spinal bölgede çap artışı T2A 
incelemelerde sinyal artışı ve T1 kontrastlı kesitlerde heterojen kontrastlanma izlendi (Resim 4A-4B-4C). DSA'da sağ D8 pedinkülünden beslenen SDAVF izlendi. Selektif olarak sağ interkostal arterin posterior spinal arter dalına girilerek fistül lokalizasyonuna ulaşılıp oradan mikrokateter içerisinden embolik bir ajan olan ethylene-vinyl alcohol copolymer (SQUID, BALT, Paris, France) ile total olarak embolizasyon yapıldı (Resim 5A-5B).

\section{TARTIŞMA}

Spinal kord, vertebral arterlerden çıkan anterior spinal arter (ASA) ve PICA ya da vertebral arterlerden ayrilan posterior spinal arterlerden (PSA) beslenir. ASA ve PSA arasinda anastomoz bulunmamakla birlikte, radiküler arterler radikülomedüller ve radikülopial arterler aracılığıyla her iki artere dallar verir. Venöz direnaj intramedüller venlerden, sırayla perimedüller, radiküler ve vertebral venöz pleksusa doğrudur (5).

SDAVF'de klinikten sorumlu olan, intervertebral foramenin dura içindeki kısmında yer alan, dural arter ve perimedüller venöz sistem arasında oluşan düşük akıma sahip şantlardır. Şant sonucunda arteriyelize hale gelen ven duvarı genişler ve tortiyozite gelişir. Genellikle tek bir besleyici artere sahiptirler, fakat rostral yönde dilate venöz damarlar kaudale doğru diğer venlere açlarak diğer segmentlerde de tortiozite görünümüne sebep olur. Ortaya çıkan venöz hipertansiyon ve konjesyon hastalarda görülen miyelopatiye neden olmaktadır. Erkeklerde ve 5-6. dekad arasında sık görülen SDAVF, nadiren genç hastalarda da görülebilmektedir. Lezyonlar genellikle tek taraflı olup lokalizasyon olarak sıklıkla torakolomber bölgede görülür ancak daha seyrek olarak servikal ve sakral bölgede de malformasyon görülen olgular bildirilmiştir. Bizim hastalarımızın tümü erkek olup, ikisi 4. dekaddaydı. Olgularımızdaki SDAVF'lerin 3 tanesi torakal, 1 tanesi lomber bölgede idi.

Hastalar sıklıkla alt ekstremite güçsüzlüğü, azalmış ağrı ve ısı duyusu, idrar ve gaita inkontinansını içeren ilerleyici miyelopati tablosuyla başvurmaktadırlar (1). Yürürken, öne eğilmekle artan ve dinlenmekle azalan șikayetler ASA sendromunu düșündürür. Hastalık sıklıkla spesifik olmayan semptom ve bulgularla seyrettiği için tanıda gecikme görülebilmektedir. Donghai ve arkadaşları yaptıkları bir çalışmada şikayetlerin başlangıcından tanı almaya kadar geçen ortalama süreyi 19,9 ay olarak belirtmişlerdir (6). En sık görülen șikayetleri alt ekstremitelerde güçsüzlük, his kaybı ve sfinkter tutulumu olarak sıralamışlardır. Nadiren intramedüller kanamaya neden olur. Fakat akut gelișen durumlarda hemoraji ön planda düşünülmelidir. Kinouchi ve ark. İntrakraniyal subaraknoid hemoraji tanısı alan bir olguda kraniyoservikal bileşkede SDAVF saptamışlardır (7). Ayırıcı tanıda spinal stenoz, akut/kronik inflamatuar demiyelinizan polinöropati, spinal kord tümörü, ALS, spinal müsküler atrofi, periferik vasküler patolojiler düşünülmelidir $(3,8)$. Tanı gecikmesi kalıcı olarak sakatlığa yol açtığından dolayı akla dural AVF gelmelidir.

Fistülün ortaya çıkma nedeni aydınlatılamamıştır. Travma sonrası gelişen olgular bildirilmiştir (9). Jeng Ying ve ark. servikal bölge omurganın en hareketli ve travmaya en açık bölgesi olmasına rağmen spinal dural AVF'lerin bu bölgede nadir gözlenmesi sebebiyle travmanın etyolojide düşünülmemesi gerektiğini ileri sürmüşlerdir (8). İkinci olgumuzda düşme öyküsü olması nedeni ile en azından bazı hastalarda etyolojide travma olabileceği düşünüldü.

Tanıda ilk başvurulması gereken yöntem manyetik rezonans görüntülemedir. Spinal kordda venöz konjesyona bağlı oluşan ödem sonucu T2 ağırlıklı görüntülemelerde saptanan sinyal artışı duyarlı bir bulgu olmasına karşın özgüllüğü düşüktür (10). Muralidharan ve arkadaşları olguların \%95'inde spinal kordun konus bölgesinde T2 ağırlıklı görüntülemelerde sinyal artışı görüldüğü bildirilmiştir (11). Görüntülemelerde kordun sıklıkla dorsal yüzünde dilate intradural venlere ait akım void görülmesi daha özgül olarak değerlendirilmiștir ancak beyin omurilik sıvısı akımının oluşturduğu artefaktlar sebebiyle değerlendirilmesi güçtür. DSA, tanıda altın standart olarak kullanılmaktadır (3).

Tedavide mikrocerrahi ve endovasküler embolizasyon kullanılmaktadır. Tedaviyle fistülün total olarak kapatılması ve fistül sebebiyle oluşan artmış intravasküler basıncı tersine çevirerek kord perfüzyonunu sağlanması amaçlanmaktadır. Endovasküler tedavinin amacı fistülü ve drenaj veninin proksimalini embolik ajanlarla oklüde etmektir (12). Cerrahi tedavi şansını ortadan kaldırmaz, minimal invazivdir. 
Endovasküler tedavinin fistül tedavisindeki yerine dair yeni çalışmalar mevcuttur. Kirsch ve arkadaşlarının yayınladı̆̆ı 78 hastalık çalışmada \%77 bașarılı tedavi oranı elde edilmiștir. Hastaların kısa dönem sonuçları, cerrahi hastalarıyla kıyaslandığında benzer bulunmuştur (13). Mikrocerrahi yöntem olarak fistülün boșaldığ spinal venin bipolar akım ile koterize edilmesi veya anevrizma klipsi ile kapatılması kullanılmaktadır (14). İntraoperatif anjiyografi kullanımı cerrahi tedavi başarısını arttırmaktadır. Koch ve ark. 34 SDAVF olgularını bildirmiş, 20'si endovasküler embolizasyon, 14'üne ise primer cerrahi tedavi uygulamıştır. Endovasküler tedavi grubunda \%85, cerrahi grupta \%90 başarı elde etmişler ve bunların istatistiksel anlamlı farklılık göstermediğini belirtmişlerdir (15). Her iki tedavi modalitesinde de hastanın operasyon öncesi kliniğinin, operasyon sonrası sonuçları etkileyen en önemli faktör olduğu bildirilmektedir (13).

Sonuç olarak SDAVF'ler nadir görülmesi ve geniş klinik spektruma sahip olması sebebiyle tanısı güçtür. Ayırıcı tanıda akla gelerek nörogörüntülemelerle tespit edilmesi, erken tedavi ile geri dönüşsüz hasarın önlenme şansı açısından önem taşımaktadır.

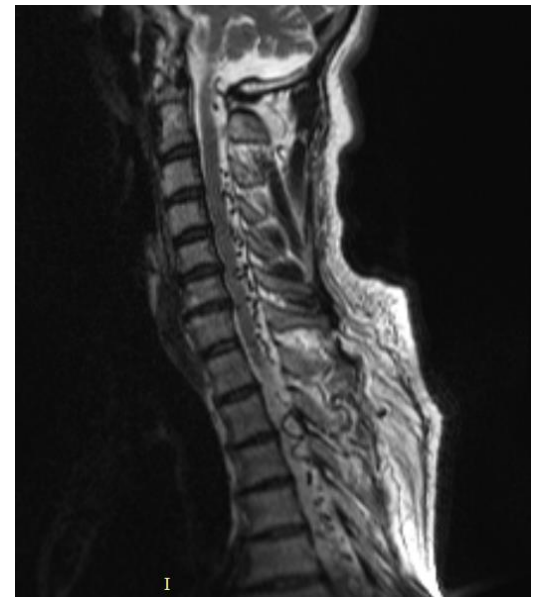

Resim 1A. Servikal T2 ağırlıklı kesitlerde C2'den başlayıp torakale uzanan kord posteriorunda anormal vasküler yapılara bağlı serpentin sinyalsiz alanlar.

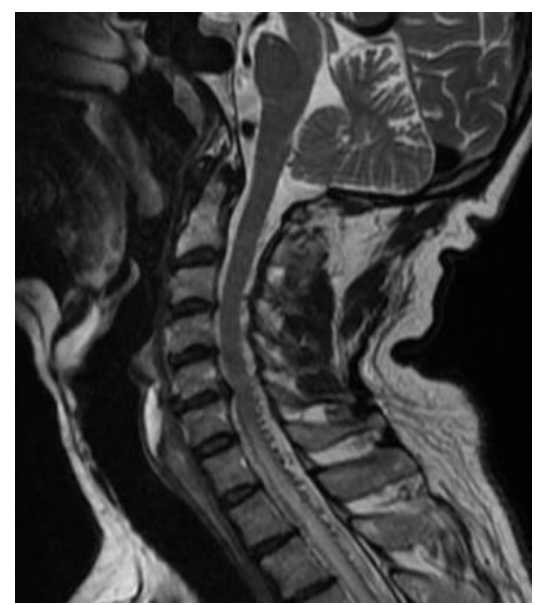

Resim 2A. C5'ten bașlayıp torakale uzanan kord santralinde sinyal artışı, posteriorda anormal vasküler yapılara bağlı serpentin sinyalsiz alanlar.

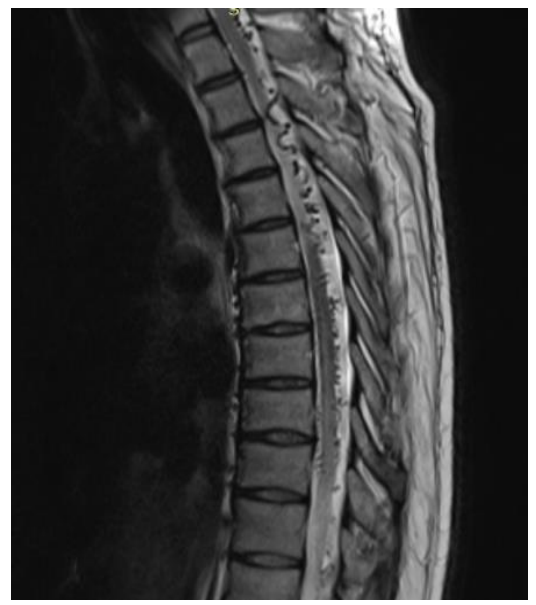

Resim 1B. Torakal T2 kesitlerde tüm segmentlerde izlenen kord posteriorunda anormal vasküler yapılara bağlı serpentin sinyalsiz alanlar.

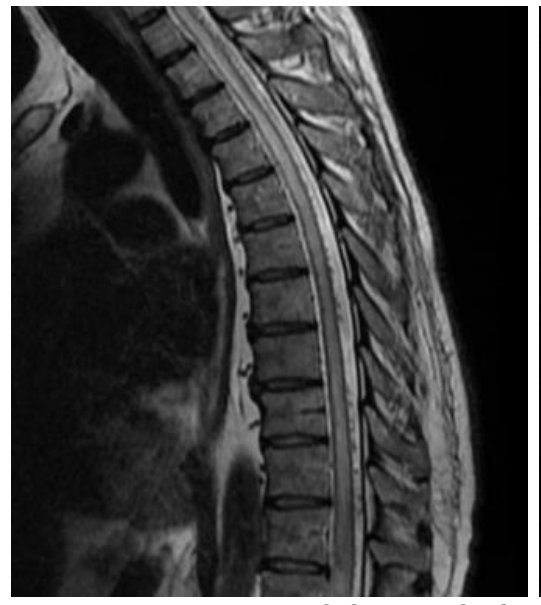

Resim 2B. Tüm torakal seviyelerde hiperintens görünüm, posteriorda milimetrik dilate signal kaybı gözlenen vasküler yapılar.

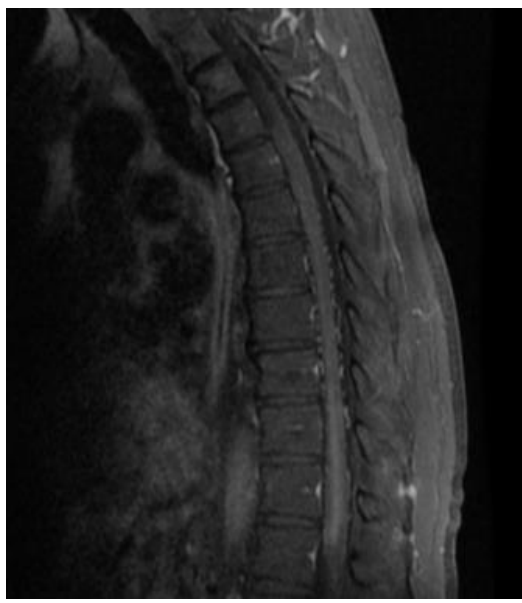

Resim 2C. Tüm torakal seviyelerde kord santralinde gözlenen lezyonun kontrast tutulumu. 


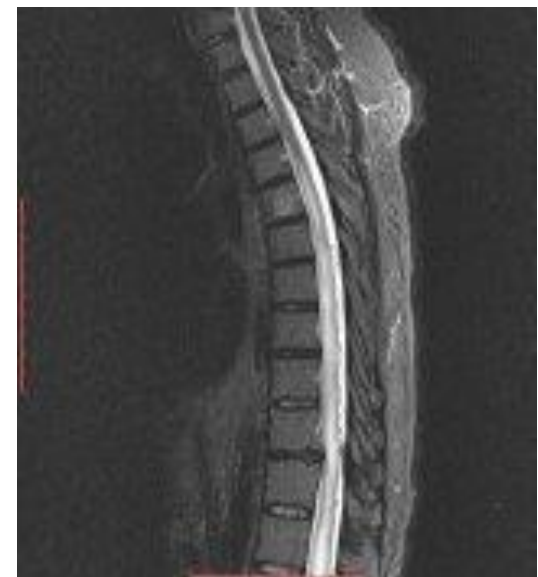

Resim 3A. Spinalkordda T4 düzeyinden başlayarak distale uzanan T2 serilerde hiperintens ekspansiyon.

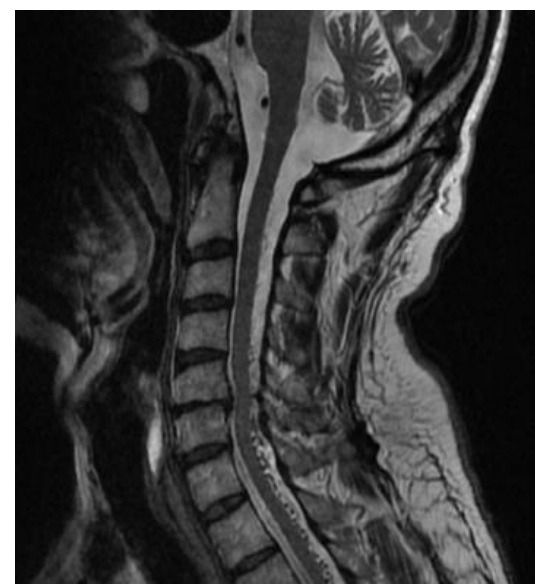

Resim 4A. Spinal kordda C3 düzeyinden bașlayarak distale uzanan T2 serilerde milimetrik dilate signal void vasküler yapılar.

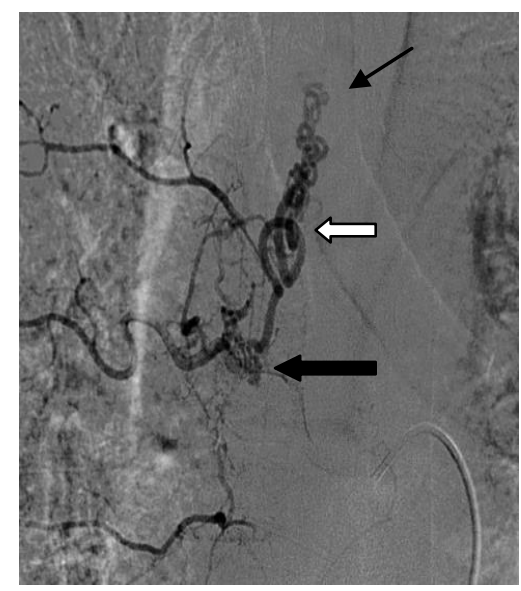

Resim 5A. Kalın siyah ok: interkostal arterin anjiografik enjeksiyonu. İnce siyah ok: Genișlemiș, tortiyöz venöz yapılar. Kalın beyaz ok: AVF.

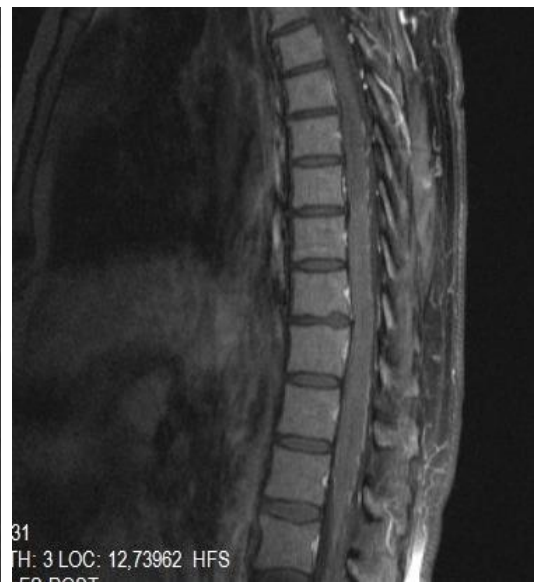

Resim 3B. T1 kontrastll kesitlerde heterojen kontrastlanma.

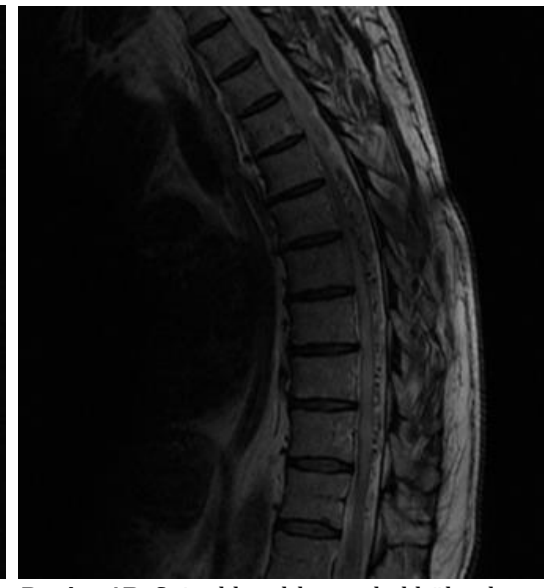

Resim 4B. Spinal kordda torakal bölgeden konuş medullarise uzanan T2 serilerde hiperintens sinyal değişikleri ve milimetrik dilate signal void vasküler yapılar.

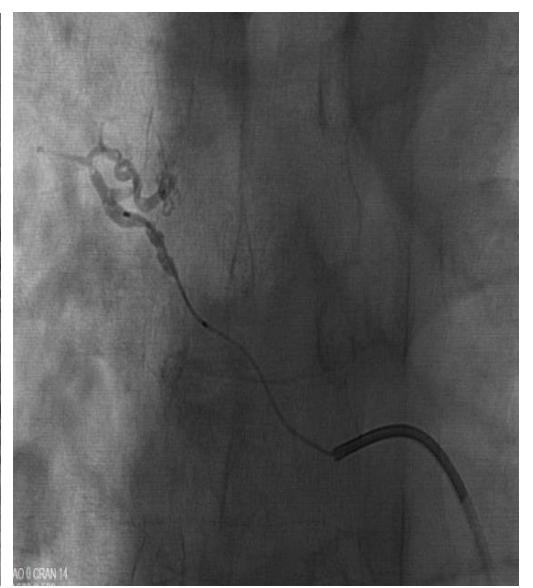

Resim 5B. Embolizan ajan uygulanması sonrası fistülün kapatıldığı gözleniyor.

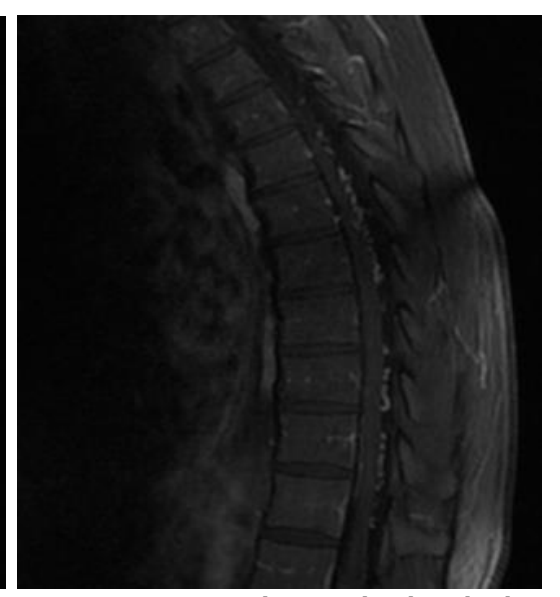

Resim 4C. T1 kontrastll kesitlerde heterojen kontrastlanma. 


\section{KAYNAKLAR}

1. Flores BC, Klinger DR, White JA, Batjer HH. Spinal vascular malformations: treatment strategies and outcome. Neurosurg Rev. 2017;40(1):15-28.

2. Amanieu C, Hermier M, Peyron N,Chabrol A, Deiana G, Manera L. Spinal dural arteriovenous fistula. Diagn Interv Imaging. 2014;95(9):897-902.

3. Krings T, Geibprasert S.Spinal Dural Arteriovenous Fistulas.AJNR Am J Neuroradiol.2009;30(4):639-48.

4. Dehdashti AR, Da Costa LB, Terbrugge KG,Willınsky RA, Tymianskı M, Wallace MC. Overview of thecurrent role of endovascular and surgical treatment in spinal dural arteriovenous fistulas.NeurosurgFocus. 2009;26(1):8.

5. Alkan Ö, Kızılkılıç O, Yıldırım T, et al. Spinal Dural Arteriyovenöz Fistülün Endovasküler Yolla Tedavisi:Olgu Sunumu. Journal of Turkish Cerebrovascular Diseases. 2009;15:(1)31-34.

6. Donghai W, Ning Y, Peng Z,Shuo X, Xueen L, Peng Z, Bin H, Xingang L.The diagnosis of spinal dural arteriovenous fistulas.Spine. 2013;38(9):546-53.

7. Kinouchi H, Mizoi K, Takahashi A, et al. Dural arteriovenous shunts at the craniocervical junction. J Neurosurg. 1998;89:755-761.

8. Jeng Y,Chen DY, Hsu HL, et al. Spinal Dural ArteriovenousFistula: Imaging Features and Its Mimics. Korean J Radiol.2015;16(5):1119-1131.
9. Jellema K, Canta LR, Tijssen CC, vanRooijWj, Koudstaal PJ, vanGijn J. Spinal dural arteriovenous fistulas: clinical features in 80 patients. J NeurolNeurosurgPsychiatry. 2003;(74):1438-1440.

10. Gilbertson JR, Miller GM, Goldman MS, et al. Spinal dural arteriovenous fistulas: MR and myelographic findings. AJNR. 1995; 16:2049-2057.

11. Muralidharan R, Saladino A, Lanzino G,Atkinson JL, Rabinstein AA. The clinical and radiological presentation of spinal dural arteriovenous fistula. Spine. 2011;36(25):1641-1647.

12. Van Dijk JM, TerBrugge KG, Willinsky RA, et al. Multidisciplinary management of spinal dural arteriovenous fistulas: clinical presentation and long-term follow-up in 49 patients.Stroke. 2002;33(6):1578-83.

13. Kirsch $\mathrm{M}$ et al. Endovascular management of spinal dural arteriovenous fistulas in 78 patients. Neuroradiology. 2013; 55: 337-343.

14. Marcus J, Schwarz J, Singh IP, et al. Spinal dural arteriovenous fistulas: A review. CurrAtherosclerRep. 2013;15(7):335.

15. Koch MJ, Stapleton CJ, Agarwalla PK, et al. Open and endovascular treatment of spinal dural arteriovenous fistulas: a 10-year experience. J NeurosurgSpine. 2017;26(4):519-523. 